\title{
December 14 Highlights and Commentary
}

\section{Behavioral and cognitive effects of cerebellar disease}

\section{Epilepsy}

The cerebellum mediates one form of procedural learning: classical conditioning of the eyeblink response. Hermann et al. demonstrate that cerebellar atrophy in epilepsy is associated with disruption of this type of conditioning.

see page 2129

\section{Posterior cerebellar infarction}

Exner et al. studied 11 subjects with cerebellar infarction in the posterior inferior cerebellar artery (PICA) vs SCA vascular territory. PICA but not SCA lesions resulted in cognitive and affective deficits.

see page 2132

\section{Cognition and the cerebellum}

\author{
Commentary by Jeremy D. Schmahmann, MD
}

Converging lines of evidence suggest that cerebellar function extends beyond the coordination of movement. Neuroanatomical data reveal topographically arranged reciprocal connections between cerebellum and cerebral association and paralimbic cortices; functional neuroimaging studies of cognition routinely activate cerebellum; and animal experiments reveal cerebellar influences on autonomic function, learning, and spatial navigation. ${ }^{1}$ The description of executive, visual-spatial, language, and mood changes - the cerebellar cognitive affective syndrome (CCAS) - following lesions confined to cerebellum in adults and children has added to the clinical weight of evidence indicating a role for the cerebellum in higher order behavior.

These developments have prompted fundamental questions, two of which are addressed by reports in this issue of Neurology. First, is there topographic organization of motor versus cognitive and affective function in the human cerebellum? Exner et al. found that in patients with cere- bellar stroke, deficits in episodic memory and executive functions, and pathology on a brief psychiatric rating scale were present in those with lesions in the PICA territory, but not in those with SCA lesions. Visual spatial working memory was impaired in both groups. The findings are consistent with new notions about cerebellar functional topography, ${ }^{2}$ and the pattern of deficits in the original report of the CCAS in which cognitive deficits were present following lesions of the cerebellar posterior lobe, and affective changes were present when the posterior vermis was involved. The PICA vs SCA distinction is necessarily broad, and studies that evaluate structure-function correlations of individual cerebellar lobules with respect to motor, cognitive, and limbic domains are needed.

Second, to what extent does cerebellar involvement in more widespread disorders contribute to the cognitive impairment traditionally ascribed to cerebral structures? Hermann et al. found that when compared to healthy con- trols, temporal lobe epilepsy (TLE) patients with cerebellar atrophy are impaired on the classically conditioned eyeblink response. The cerebellum (lobule VI and the interpositus nucleus) is both necessary and sufficient for this form of learning. Therefore this study indicates a specific cerebellar contribution to the pattern of cognitive performance in this population. It would be helpful to know if there is a difference in eyeblink conditioning between the TLE populations with and without cerebellar atrophy. Nevertheless this study raises the possibility that aspects of the CCAS may contribute to neurobehavioral impairment in patients who have cerebellar as well as cerebral lesions.

\section{References}

1. Schmahmann JD. ed. The cerebellum and cognition. International review of neurobiology, Volume 47. San Diego: Academic Press, 1997.

2. Schmahmann JD. Disorders of the cerebellum: ataxia, dysmetria of thought, and the cerebellar cognitive affective syndrome. J Neuropsychiatry Clin Neurosci 2004;16:367-378.

see pages 2129 and 2132 


\title{
Neurology
}

\author{
December 14 Highlights and Commentary \\ Neurology 2004;63;1991 \\ DOI 10.1212/WNL.63.11.1991
}

This information is current as of December 13, 2004

Updated Information \& Services

References

Permissions \& Licensing

Reprints including high resolution figures, can be found at: http://n.neurology.org/content/63/11/1991.full

This article cites 1 articles, 0 of which you can access for free at: http://n.neurology.org/content/63/11/1991.full\#ref-list-1

Information about reproducing this article in parts (figures,tables) or in its entirety can be found online at:

http://www.neurology.org/about/about_the_journal\#permissions

Information about ordering reprints can be found online:

http://n.neurology.org/subscribers/advertise

Neurology ${ }^{\circledR}$ is the official journal of the American Academy of Neurology. Published continuously since 1951, it is now a weekly with 48 issues per year. Copyright . All rights reserved. Print ISSN: 0028-3878. Online ISSN: 1526-632X.

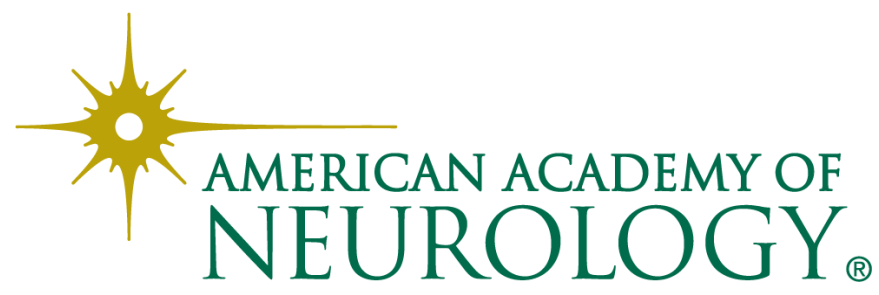

